\title{
DIFFUSIONAL FLOW UNDER NON-ISOTHERMAL LAMINAR FREE CONVECTION AT A THERMAL CONVECTIVE ELECTRODE*
}

\author{
S. L. Marchiano and A. J. Arvía \\ Instituto Superior de Investigaciones, Facultad de Quimica y Farmacia and \\ Departamento de Ingenieria Quimica, Facultad de Ciencias Fisicomatemáticas, \\ Universidad Nacional de La Plata, Argentina
}

\begin{abstract}
A theoretical solution for the set of differential equations related to laminar free convection under simultaneous concentration and thermal gradients, at an ideal vertical plate electrode, is attempted.

The rate equation comprises the limiting case of isothermal free convection and presents a relationship between the maximum average flux and the temperature gradient that is qualitatively coincident with previous experimental results. Velocity and concentration distributions in the boundary layer are evaluated.

Résumé-On a tenté une solution théorique des équations différentielles compliquées par dans un électrode ideale plane et verticale avec convection libre et gradients thermique et de concentration simultanés. On a évalué les distributions de concentration et de vitesse dans des couches limites.

L'équation de débit comprend le cas limite de convection libre isothermique et elle présente une dépendence de la vitesse moyenne du procassus avec le gradient de température qui montre une concordance qualitative avec des données experimentales prealables.
\end{abstract}

Zusammenfassung-Es wird versucht, eine theoretische Lösung für die Differentialgleichungen der laminaren freien Konvektion an einer idealen senkrechten Plattenelektrode, an welcher gleichzeitige Konzentrations- und Wärmegradienten, vorhanden sind aufzustellen.

Die Geschwindigkeitsgleichung schliesst den Grenzfall der isothermien freien Konvektion ein und zeigt eine Beziehung zwischen dem maximalen mittleren Fluss und dem Temperaturgradienten, welche qualitativ mit vorhergehenden experimentellen Resultaten übereinstimmt.

Die Geschwindigkeits- und Konzentrationsverteilungen in der Grenzschicht wurden abgeschätzt.

MASS-TRANSFER phenomena play an important part in electrochemical kinetics as well as in heterogeneous reactions in general, as described in the literature. ${ }^{1,2}$ Generally the solutions of the differential mass-transfer equations applied to electrochemistry refer to isothermal systems.

In the case of isothermal laminar free convection the solutions of the differential mass-transfer equations have already been studied for a vertical plate, yielding local rate equations of the form ${ }^{1.3-8}$

$$
j=K D\left(\frac{v}{D}\right)^{1 / 4}\left(\frac{g \alpha}{\nu^{2}}\right)^{1 / 4} C_{0} x^{-1 / 4}
$$

The meaning of the symbols is given later; $K$ is a numerical constant depending on the approximations made in the mathematical deductions.

Analogously, the differential heat-transfer equations for vertical plates under free convection have been solved by various authors ${ }^{9-11}$ and the local flux equations, mutatis mutandis, have the same form as (1).

Buoyancy effects caused by both temperature and concentration gradients were considered in a recent publication in order to get a reasonable idea of the influence of relevant parameters to transport processes involved in binary diffusion and heat transfer in the laminar free convection boundary layer on a vertical plate. ${ }^{\mathbf{1 2}}$

- Manuscript received 25 September 1967. 
Recently, experiments on the increase of the mass-transfer rate due to thermal convection were reported..$^{13}$ An attempt was made to present a new electroanalytical technique based on the so-called thermal convective electrode.

Some years ago the same effect had been observed in this laboratory, ${ }^{14}$ but the results were not published since a solution of the non-linear set of coupled equations related to the problem involving simultaneous gradients of temperature and concentration, under laminar free convection and a fixed geometry, was not then found. The purpose of this paper is to present an approach to the theory of a thermal convective electrode.

\section{DIFFERENTIAL EQUATIONS AND BOUNDARY CONDITIONS}

To solve the mass-transfer problem under combined effect of temperature and concentration gradients, the simultaneous solution of the transfer equations related to momentum, energy and mass must be attempted.

For the particular case of a vertical plate under buoyancy forces only, the momentum-transfer equation is

$$
v_{x} \frac{\partial v_{x}}{\partial x}+v_{y} \frac{\partial v_{x}}{\partial y}=\nu \frac{\partial^{2} v_{x}}{\partial y^{2}}+g \frac{\left(\rho_{0}-\rho\right)}{\rho_{0}},
$$

where $x$ is the coordinate defined along the plate and $y$ is the direction perpendicular to it, $v_{x}$ and $v_{y}$ are the velocity components in the $x$ and $y$ directions respectively, $v$ is the kinematic viscosity, $g$ the gravity, $\rho_{0}$ a reference density and $\rho$ a density that is a function of the concentration and temperature.

The mass- and energy-transfer equations are respectively

and

$$
v_{x} \frac{\partial C}{\partial x}+v_{y} \frac{\partial C}{\partial y}=D \frac{\partial^{2} C}{\partial y^{2}}
$$

$$
v_{x} \frac{\partial T}{\partial x}+v_{y} \frac{\partial T}{\partial y}=\frac{k}{\rho C_{p}} \frac{\partial^{2} T}{\partial y^{2}},
$$

where $C$ is the concentration of the diffusing species, $D$ its diffusion coefficient, $T$ the temperature, $k$ the thermal conductivity and $C_{p}$ the specific heat at constant pressure. The boundary conditions for this set of differential equations are

$$
\begin{gathered}
y=0\left\{\begin{array}{l}
v_{x}=v_{y}=0 \\
C=0 \\
T=T_{1}
\end{array}\right. \\
y=\infty\left\{\begin{array}{l}
v_{x}=v_{y}=0 \\
C=C_{0} \\
T=T_{0}
\end{array}\right\} .
\end{gathered}
$$

\section{Total differential equations}

To solve (2), (3) and (4) we transform them into a set of total differential equations. By taking into account that the density is a weak function of concentration and temperature, it can be conveniently expressed by

$$
\rho=\rho_{0}+\frac{\partial \rho}{\partial C}\left(C-C_{0}\right)+\frac{\partial \rho}{\partial T}\left(T-T_{0}\right)
$$


It is also convenient, for the subsequent analysis, to introduce the densification and expansion coefficients, $\alpha$ and $\beta$, respectively, as is usually done in dealing with the individual cases of isothermal free convection and free heat transfer. They are

$$
\alpha=\frac{C_{0}}{\rho_{0}} \frac{\partial \rho}{\partial C}
$$

and

$$
\beta=\frac{\Delta T}{\rho_{0}} \frac{\partial \rho}{\partial T}
$$

where $\Delta T=T_{0}-T_{1}$.

Following the procedure used to solve the mass-transfer differential equation under free convection, ${ }^{1}$ we define now a new independent dimensionless variable, $\mu$, by

$$
\mu=\left(\frac{g}{4 v^{2}}\right)^{1 / 4} \frac{y}{x^{1 / 4}}
$$

We also define a dimensionless concentration, $\varphi$, and temperature, $\tau$, as

and

$$
\varphi=\frac{C_{0}-C}{C_{0}}
$$

$$
\tau=\frac{T_{0}-T}{T_{0}-T_{1}}
$$

The velocity component in terms of the streaming function $\psi$, is defined as a function of $\mu$, in the following form,

$$
\psi=4 v\left(\frac{g}{4 v^{2}}\right)^{1 / 4} x^{3 / 4} f(\mu)
$$

Then, we have

and

$$
v_{x}=\frac{\partial \psi}{\partial y}=4 \nu\left(\frac{g}{4 v^{2}}\right)^{1 / 2} x^{1 / 2} f^{\prime}(\mu)
$$

$$
v_{y}=-\frac{\partial \psi}{\partial x}=v\left(\frac{g}{4 v^{2}}\right)^{1 / 4}\left(\frac{\mu f^{\prime}(\mu)-3 f(\mu)}{x^{1 / 4}}\right),
$$

where $f(\mu)$ and $f^{\prime}(\mu)$ are respectively functions of the variable $\mu$ and its first derivative, which satisfy

$$
f^{\prime \prime \prime}+3 f^{\prime \prime}-2 f^{\prime 2}+\alpha \varphi+\beta \tau=0 .
$$

Similarly, the new total differential equations for mass and energy transfer, in terms of $\varphi$ and $\tau$, are respectively

$$
\begin{aligned}
\varphi^{\prime \prime}+3 S c f \varphi^{\prime} & =0, \\
\tau^{\prime \prime}+3 P r f \tau^{\prime} & =0,
\end{aligned}
$$

where the primes correspond to the order of the derivatives; $S c$ is the Schmidt number defined by

$$
S c=\frac{\nu}{D}
$$


and $P r$ is the Prandlt number given by

$$
\operatorname{Pr}=\frac{\nu \rho C_{p}}{k}
$$

The boundary conditions related to (15), (16) and (17) are

\section{Distribution functions}

$$
\mu=0\left\{\begin{array}{l}
f=f^{\prime}=0 \\
\varphi=1 \\
\tau=1
\end{array} ; \quad \mu=\infty\left\{\begin{array}{l}
f^{\prime}=0 \\
\varphi=0 \\
\tau=0
\end{array}\right.\right.
$$

To obtain the distribution function related to mass transfer under thermal convection, let us first consider the following two limiting cases, (i) isothermal free convection under a concentration gradient and (ii) thermal free convection.

Case (i). For isothermal free convection, $\Delta T=0$ and consequently the set of total differential equations is reduced to (15) and (16), which have been analysed by different authors. ${ }^{1.6}$ To establish the concentration distribution Levich assumes that the function $f$ can be expressed as a series expansion in powers of $\eta$, as follows:

$$
f(\eta)=\frac{A_{\eta}}{2} \eta^{2}-\frac{\eta^{3}}{6}+\left(\frac{A_{\eta} S c}{2}\right)^{1 / 3} \frac{\eta^{4}}{24 \times 0.89}
$$

where

$$
\eta=\left(\frac{g \alpha}{4 v^{2}}\right)^{1 / 4} \frac{y}{x^{1 / 4}}
$$

Taking into account the boundary conditions, the constant $A_{\eta}$ is

$$
A_{\eta}=\frac{0 \cdot 48}{S c^{1 / 4}}
$$

The concentration distribution becomes

$$
\varphi=1-\frac{\left(\frac{0.48}{2}\right)^{1 / 3} S c^{1 / 4}}{0.89} \eta
$$

Case (ii). Analogously, when there is no concentration gradient, the set of equations is that of the corresponding heat-transfer problem. Following basically the assumptions of case (i), which means that the convergence of the integrals in $\tau$ may be in a first approximation, and for $\operatorname{Pr}$ number of about 10 or larger, comparable to that of $\varphi$,

$$
f(\lambda)=\frac{A_{\lambda}}{2} \lambda^{2}-\frac{\lambda^{3}}{6}+\left(\frac{A_{\lambda} \operatorname{Pr}}{2}\right)^{1 / 3} \frac{\lambda^{4}}{24 \times 0.89}
$$

where

$$
\lambda=\left(\frac{g \beta}{4 v^{2}}\right)^{1 / 4} \frac{y}{x^{1 / 4}}
$$

and

$$
A_{\lambda}=\frac{0.48}{\operatorname{Pr}^{1 / 4}}
$$


Similarly as in case (i), the temperature distribution is

$$
\tau=1-\frac{\left(\frac{0.48}{2}\right)^{1 / 3} \operatorname{Pr}^{1 / 4}}{0.89} \lambda
$$

Case (iii). To attack the problem of combined contributions of gradients of concentration and temperature, we assume that its streaming function is the algebraic sum of the streaming functions of cases (i) and (ii). Then according to (12), (21) and (25), we have

$$
\begin{aligned}
\psi=4 v\left(\frac{g}{4 v^{2}}\right)^{1 / 4} x^{3 / 4}\{ & {\left[A_{\eta} \alpha^{3 / 4} \pm A_{\lambda} \beta^{3 / 4}\right] \frac{\mu^{2}}{2}-\frac{\alpha \pm \beta}{6} \mu^{3} } \\
& \left.+\left[\left(A_{\eta} S c\right)^{1 / 3} \alpha^{5 / 4} \pm\left(A_{\lambda} P r\right)^{1 / 3} \beta^{5 / 4}\right] \frac{\mu^{4}}{2^{1 / 3} \times 24 \times 0.89}\right\}
\end{aligned}
$$

By comparison of (29) with (12), the term in braces corresponds to $f(\mu)$. Consequently the distribution equation, for the velocity component in the $x$ direction, is obtained immediately from (13) as

$$
\begin{array}{r}
v_{x}=4 \nu\left(\frac{g}{4 v^{2}}\right)^{1 / 2} x^{1 / 2}\left\{0.48\left[\frac{\alpha^{3 / 4}}{S c^{1 / 4}} \pm \frac{\beta^{3 / 4}}{\operatorname{Pr} 1 / 4}\right] \mu-\frac{\alpha \pm \beta}{2} \mu^{2}+\frac{(0 \cdot 24)^{1 / 3}}{6 \times 0.89}\left[S c^{1 / 4} \alpha^{5 / 4}\right.\right. \\
\left.\left. \pm \operatorname{Pr}^{1 / 4} \beta^{5 / 4}\right] \mu^{3}\right\}
\end{array}
$$

It is interesting for the sake of comparison to evaluate the velocity profile in terms of $v_{x}$ and $y$ for cases (i), (ii) and (iii). The following calculations refer to an actual system at a constant length equal to unity having the properties indicated in Table 1, as well as the conditions of temperature and concentration used.

TABle 1. Parameters for NUMerical CAlCulations

\begin{tabular}{cccccccccc}
\hline $\begin{array}{c}\Delta T \\
{ }^{\circ} \mathrm{C}\end{array}$ & $\begin{array}{c}T_{0} \\
{ }^{\circ} \mathrm{C}\end{array}$ & $\begin{array}{c}T_{1} \\
{ }^{\circ} \mathrm{C}\end{array}$ & $\begin{array}{c}C \\
\mathrm{M}\end{array}$ & $\begin{array}{c}D \times 10^{8} \\
\mathrm{~cm}^{2} / \mathrm{s}\end{array}$ & $\begin{array}{l}\nu \times 10^{2} \\
\mathrm{~cm}^{2} / \mathrm{s}\end{array}$ & $S c$ & $P r$ & $\alpha \times 10^{4}$ & $\beta \times 10^{4}$ \\
\hline-15 & 12.5 & 5 & 0.05 & 3.16 & 1.760 & 5590 & $9 \cdot 1$ & 71.8 & 64.9 \\
+15 & 27.5 & 35 & 0.05 & 6.60 & 0.826 & 1250 & 6.6 & 71.8 & 66.1 \\
-15 & 12.5 & 5 & 0.005 & 3.16 & 1.760 & 5590 & 9.1 & 7.18 & 64.9 \\
+15 & 27.5 & 35 & 0.005 & 6.60 & 0.826 & 1250 & 6.6 & 7.18 & 66.1 \\
\hline
\end{tabular}

$x=1 \mathrm{~cm}$.

Physiochemical properties are taken as concentration-independent for the sake of calculation. This situation is actually approached when $C$ is the concentration of a diffusing ion in the presence of a large excess of a supporting electrolyte. The thermal dependence of the properties were taken from the literature..$^{15-17}$

The physiochemical properties entering the mass-transfer contribution are referred to the temperature of the plate $\left(T_{1}\right)$ whereas those related to the heat-transfer contribution were taken at average temperature $\left(T_{0}\right)$. This criterion was applied taking into account that the variation of those properties affecting the respective transport phenomena occur at widely different distances. After choosing a set of $\eta, \lambda$ and $\mu$, the functions $f$ and their derivatives were calculated. Tables 2 and 3 
TABLE 2

\begin{tabular}{|c|c|c|c|c|}
\hline \multicolumn{3}{|c|}{$T_{0}=T_{1}=5^{\circ} \mathrm{C}$} & \multicolumn{2}{|c|}{$T_{0}=T_{1}=35^{\circ} \mathrm{C}$} \\
\hline $\begin{array}{l}\eta \\
0 \\
0 \cdot 01 \\
0.05 \\
0 \cdot 07 \\
0 \cdot 08 \\
0 \cdot 09 \\
0 \cdot 10 \\
0 \cdot 12 \\
0 \cdot 15 \\
0 \cdot 20\end{array}$ & $\begin{array}{c}f(\eta) \times 10^{6} \\
0 \\
2 \cdot 60 \\
50 \cdot 1 \\
84 \cdot 2 \\
95 \cdot 3 \\
120 \\
136 \\
301 \\
491 \\
-\end{array}$ & $\begin{array}{c}f^{\prime}(\eta) \times 10^{4} \\
0 \\
5.06 \\
16 \cdot 6 \\
17.9 \\
17.6 \\
16.8 \\
15.6 \\
12 \cdot 0 \\
4.80 \\
-\end{array}$ & $\begin{array}{c}f(\eta) \times 10^{6} \\
0 \\
3 \cdot 80 \\
79 \cdot 3 \\
141 \\
175 \\
212 \\
248 \\
320 \\
421 \\
535\end{array}$ & $\begin{array}{c}f^{\prime}(\eta) \times 10^{4} \\
0 \\
7 \cdot 42 \\
28 \cdot 0 \\
33 \cdot 3 \\
35 \cdot 0 \\
36 \cdot 0 \\
36 \cdot 3 \\
35 \cdot 2 \\
30 \cdot 3 \\
14 \cdot 5\end{array}$ \\
\hline \multicolumn{3}{|c|}{$(\eta)_{\varphi=0}=0.165$} & \multicolumn{2}{|c|}{$(\eta)_{\varphi=0}=0.240$} \\
\hline \multicolumn{5}{|c|}{$\begin{array}{l}\text { TABLE } 3 \\
2^{2}-\frac{\lambda^{8}}{6}+\frac{(0.24)^{1 / 3}}{24 \times 0.89} \operatorname{Pr}^{1 / 4} \lambda^{4} . \\
\lambda-\frac{\lambda^{2}}{2}+\frac{(0.24)^{1 / 3}}{6 \times 0.89} \operatorname{Pr}^{1 / 4} \lambda^{3} .\end{array}$} \\
\hline$\lambda$ & $\begin{aligned} T_{1}= & 5^{\circ} \mathrm{C} ; \quad T_{0} \\
& f(\lambda) \times 10^{4}\end{aligned}$ & $\begin{array}{l}2 \cdot 5^{\circ} \mathrm{C} \\
f^{\prime}(\lambda) \times 10^{4}\end{array}$ & $\begin{array}{l}=35^{\circ} \mathrm{C} \\
f(\lambda) \times 10^{4}\end{array}$ & $\begin{aligned} T_{0}= & 27.5^{\circ} \mathrm{C} \\
& f^{\prime}(\lambda) \times 10^{4}\end{aligned}$ \\
\hline $\begin{array}{l}0 \\
0.10 \\
0.20 \\
0.25 \\
0.30 \\
0.35 \\
0.40 \\
0.45 \\
0.50 \\
0.60 \\
0.70 \\
0.80 \\
0.90\end{array}$ & $\begin{array}{l}0 \\
12 \cdot 1 \\
54 \cdot 8 \\
62 \cdot 3 \\
83 \cdot 3 \\
105 \\
127 \\
148 \\
169 \\
203 \\
229 \\
241 \\
-\end{array}$ & $\begin{array}{r}0 \\
228 \\
368 \\
409 \\
433 \\
441 \\
434 \\
412 \\
384 \\
298 \\
178 \\
50 \\
-\end{array}$ & $\begin{array}{c}0 \\
13 \cdot 4 \\
47 \cdot 4 \\
69 \cdot 6 \\
93 \cdot 8 \\
120 \\
145 \\
171 \\
196 \\
204 \\
278 \\
301 \\
310\end{array}$ & $\begin{array}{r}0 \\
252 \\
415 \\
462 \\
500 \\
517 \\
519 \\
507 \\
483 \\
402 \\
288 \\
152 \\
6\end{array}$ \\
\hline
\end{tabular}

refer to cases (i) and (ii) and Tables 4 and 5 comprise case (iii) under two extreme situations as described later.

The velocity profiles are plotted in Figs. 1-3, showing various interesting features. The velocity profile for case (i) is shown in Fig. 1 for two different concentrations and temperatures. The curves exhibit the usual maxima, diminishing and shifting toward higher $y$ at lower concentration of the diffusing species. The profiles are completely developed in the same range of $y$ as the concentration profiles $\left(y_{0}\right)$. Figure 2 corresponds to the velocity profiles for case (ii). The maximum velocities are much larger than for case (i) and the profiles extend to higher $y$ values. In Fig. 3 velocity profiles for two different concentrations and temperatures are shown. For each concentration two particular cases are considered, one in which the buoyancy forces 
TABLE 4

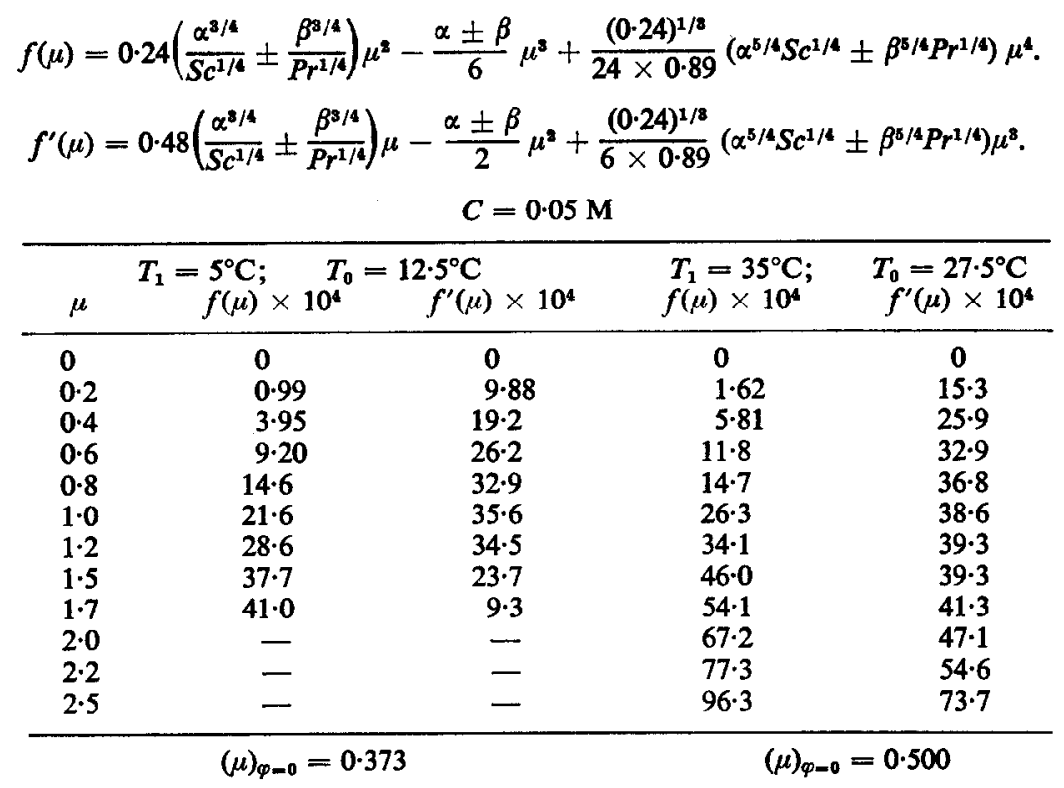

TABLE 5

$C=0.005 \mathrm{M}$

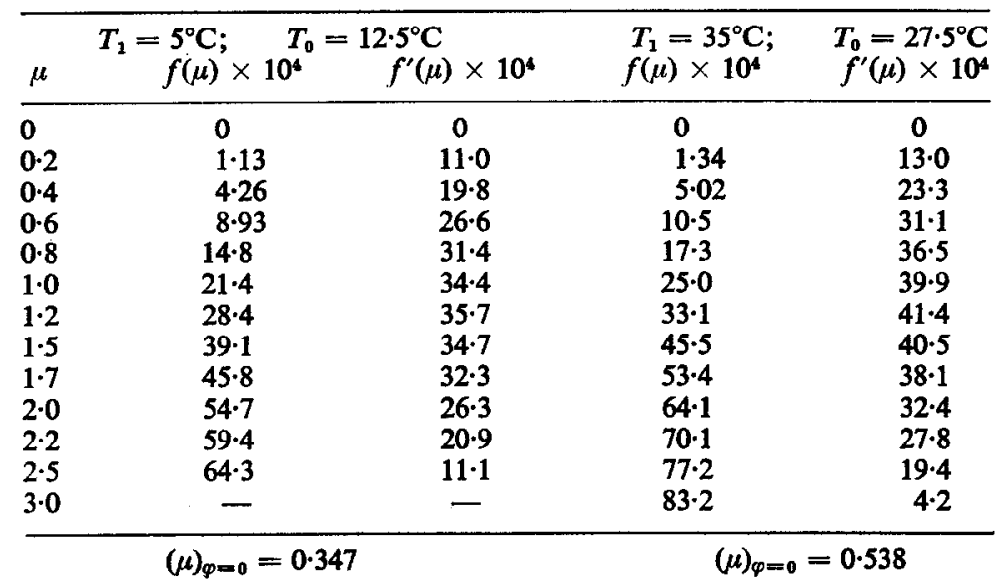

arising from the existence of both temperature and concentration gradients are added, and another where they are substracted. For the former, when the factor $\alpha$ is about the same as $\beta$, the maximum becomes an inflexion point due to the influence of the function related to $f(\eta)$ for large values of $y$, which are not taken into account in the simpler case. In this particular case the boundary condition $f^{\prime}(\mu)=0$ when $\mu=\mu_{0}$ is actually not fulfilled. However, the concentration distribution is not affected to any great extent under such circumstances because for its evaluation only the first term of the series expansion of $f(\mu)$ is considered. Furthermore, Fig. 3 reveals a greater influence of the thermal gradient in the magnitude of the velocity component for the combined case. 


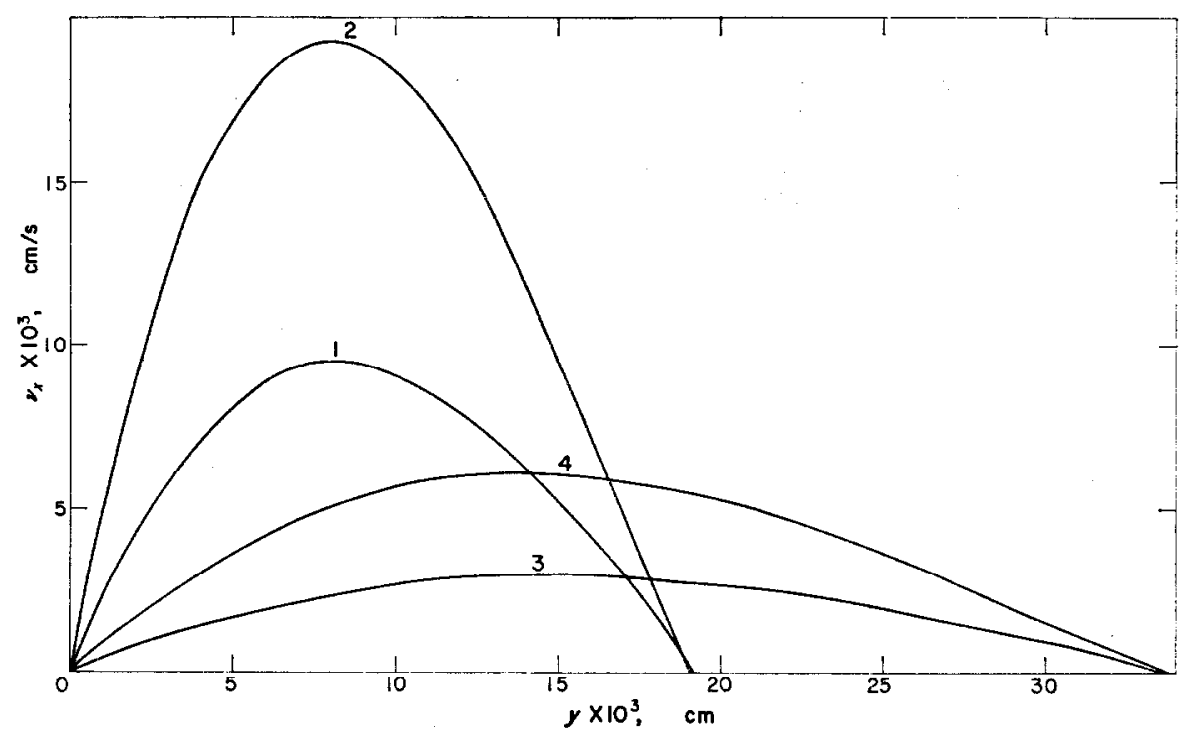

FIG. 1. Velocity $\left(v_{x}\right)$ distribution in boundary layer for isothermal laminar free convection, at $x=1 \mathrm{~cm}$.

1, $5^{\circ} \mathrm{C} ; C, 0.05 \mathrm{M} \quad 2,35^{\circ} \mathrm{C} ; C, 0.05 \mathrm{M}$

$3,5^{\circ} \mathrm{C} ; C, 0.005 \mathrm{M} \quad 4,35^{\circ} \mathrm{C} ; C, 0.005 \mathrm{M}$.

FIo. 2. Velocity $\left(v_{s}\right)$ distribution in boundary layer for thermal free convection, at $x=1 \mathrm{~cm}$.

$1, \Delta T,-15^{\circ} \mathrm{C} ; T_{0}=12.5^{\circ} \mathrm{C}$

$2, \Delta T,+15^{\circ} \mathrm{C} ; T_{0}=27 \cdot 5^{\circ} \mathrm{C}$.

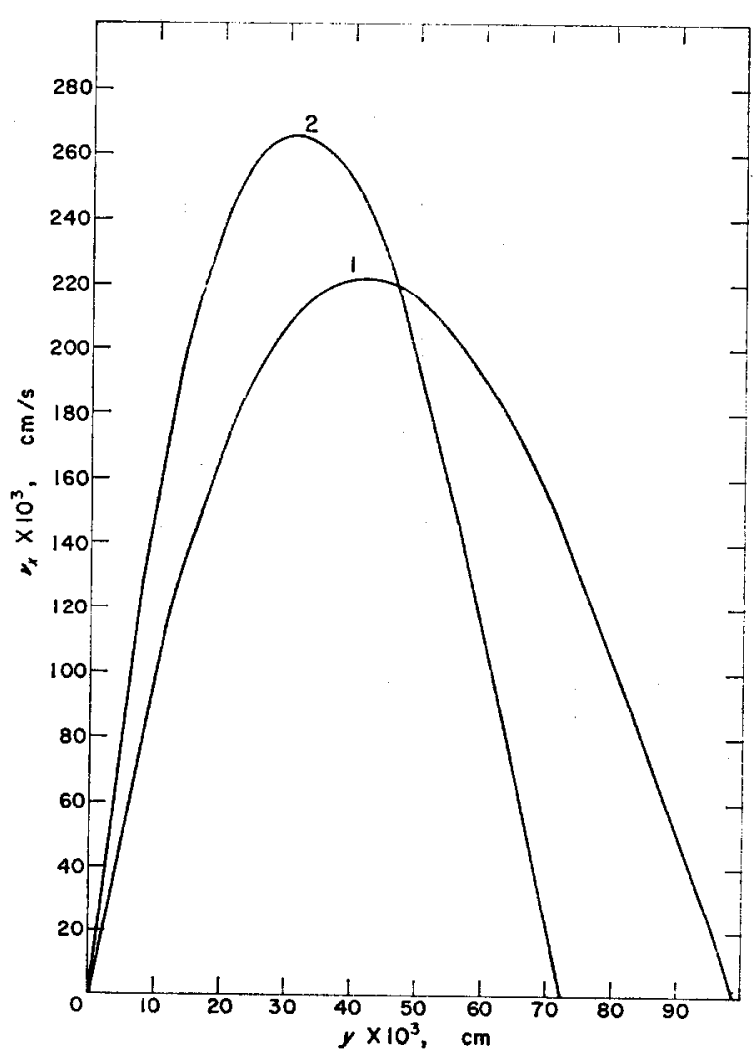




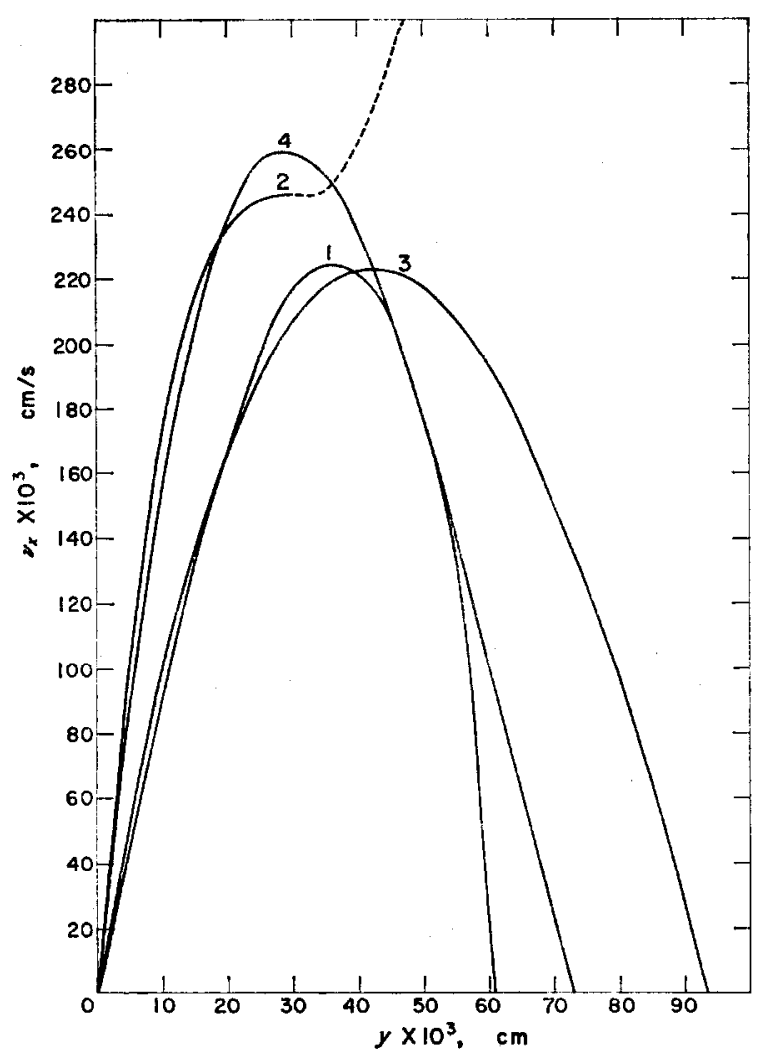

FIG. 3. Velocity $\left(v_{\text {e }}\right)$ distribution in boundary layer for simultaneous temperature and concentration gradients at $x=1 \mathrm{~cm}$.

$$
\begin{aligned}
& 1, \Delta T=-15^{\circ} \mathrm{C} ; T_{0}=12.5^{\circ} \mathrm{C} ; C, 0.05 \mathrm{M} \\
& 2, \Delta T=+15^{\circ} \mathrm{C} ; T_{0}=27 \cdot 5^{\circ} \mathrm{C} ; C, 0.05 \mathrm{M} \\
& 3, \Delta T=-15^{\circ} \mathrm{C} ; T_{0}=12.5^{\circ} \mathrm{C} ; C, 0.005 \mathrm{M} \\
& 4, \Delta T=+15^{\circ} \mathrm{C} ; T_{0}=27.5^{\circ} \mathrm{C} ; C, 0.005 \mathrm{M} .
\end{aligned}
$$

By solving (16) taking into account the boundary conditions (20) we obtain

$$
\varphi=1-\frac{\int_{0}^{\mu} \exp \left[-3 S c \int_{0}^{\mu} f(\mu) \mathrm{d} \mu\right] \mathrm{d} \mu}{\int_{0}^{\infty} \exp \left[-3 S c \int_{0}^{\infty} f(\mu) \mathrm{d} \mu\right] \mathrm{d} \mu} .
$$

If $f(\mu)$ is substituted by the first term of (29) assuming that the type of approximation formulated for case (i) and case (ii) is also permissible in the present circumstances, we have

$$
\varphi=1-\frac{(0 \cdot 24)^{1 / 3}\left(\frac{\alpha^{3 / 4}}{S c^{1 / 4}} \pm \frac{\beta^{3 / 4}}{\operatorname{Pr}^{1 / 4}}\right)^{1 / 3} S c^{1 / 3}}{0.89} \mu .
$$

Returning now to the original variables, we obtain the following distribution equation for concentration,

$$
C=0.70 C_{0}\left(\frac{\alpha^{3 / 4}}{S c^{1 / 4}} \pm \frac{\beta^{3 / 4}}{\operatorname{Pr}^{1 / 4}}\right)^{1 / 3} S c^{1 / 3}\left(\frac{g}{4 v^{2}}\right)^{1 / 4} \frac{y}{x^{1 / 4}}
$$


A plot of the concentration profile in terms of $\varphi$ and $y$ is shown in Fig. 4 for cases (i) and (iii). It becomes evident that the gradient of the concentration function is greater for the case of a combined contribution. Consequently the thickness of the diffusion layer for the latter $\left([y]_{\varphi=0}=\delta_{a}\right)$, at a constant electrode height, diminishes.

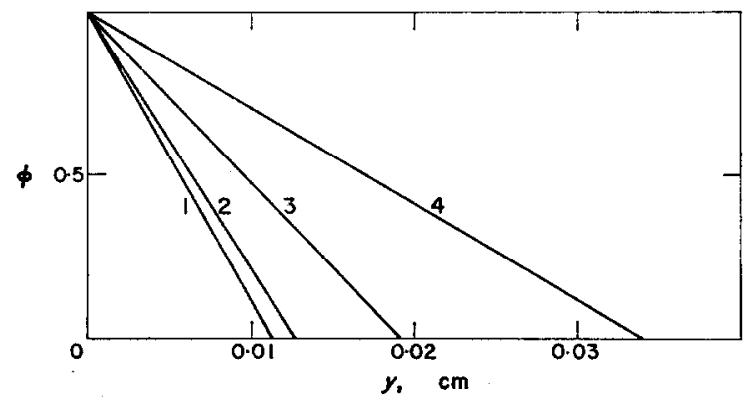

Frg. 4. Concentration distribution in boundary layers.

1 , Case (iii), $C, 0.05 \mathrm{M} ; \Delta T=+15^{\circ} \mathrm{C} ; T_{0}=27.5^{\circ} \mathrm{C}$

2, Case (iii), C, $0.005 \mathrm{M} ; \Delta T=+15^{\circ} \mathrm{C}, T_{0}=27.5^{\circ} \mathrm{C}$

3, Case (i), $C, 0.05 \mathrm{M} ; \Delta T=0^{\circ} \mathrm{C}, T_{0}=5^{\circ} \mathrm{C}$

4, Case (i), $C, 0.005 \mathrm{M} ; \Delta T=0^{\circ} \mathrm{C}, T_{0}=5^{\circ} \mathrm{C}$.

The mass-transfer equation

The local maximum diffusional flux under the effect of simultaneous temperature and concentration gradients and laminar conditions in a vertical plate $(y=0)$, is obtained with Fick's law and (33) as follows,

$$
j=D\left(\frac{\partial C}{\partial y}\right)_{y=0}=0 \cdot 70 D C_{0}\left(\frac{\alpha^{3 / 4}}{S c^{1 / 4}} \pm \frac{\beta^{3 / 4}}{P r^{1 / 4}}\right)^{1 / 3} S c^{1 / 3}\left(\frac{g}{4 y^{2}}\right)^{1 / 4} x^{-1 / 4}
$$

Integrating (34) over the surface of the plate we obtain the total maximum flux

$$
J=0.90 D C_{0}\left(\frac{\alpha^{3 / 4}}{S c^{1 / 4}} \pm \frac{\beta^{3 / 4}}{\operatorname{Pr}^{1 / 4}}\right)^{1 / 3} S c^{1 / 3}\left(\frac{g}{4 v^{2}}\right)^{1 / 4} X^{3 / 4} b,
$$

where $X$ is the electrode height and $b$ is the width of the plate in the $z$ direction. Hence the average maximum flux, $J$, is

$$
J=0.90 D C_{0}\left(\frac{\alpha^{3 / 4}}{S c^{1 / 4}} \pm \frac{\beta^{3 / 4}}{\operatorname{Pr}^{1 / 4}}\right)^{1 / 3} S c^{1 / 3}\left(\frac{g}{4 v^{2}}\right)^{1 / 4} X^{-1 / 4}
$$

Equation (36) can be plotted taking $J$ as a function of $\pm \Delta T$, as shown in Figs. 5 and 6 on the basis of Table 1 . The curves are characterized by a very rapid initial increase of $J$ with $\pm \Delta T$.

In Figs. 5 and 6, curves 1 are calculated with (36) for negative $\Delta T$ values and a simultaneous decrease of the temperature of the plate and the reference temperature of the system. Curves 2 are also given for negative $\Delta T$ values, at constant temperature of the plate and increasing reference temperature of the system. Curves 3 correspond to positive $\Delta T$ values, constant plate temperature and reference temperature decreasing. Finally curve 4 also corresponds to positive $\Delta T$ at increasing both the plate and reference temperature. Figures 5 and 6 show various remarkable features. When $\Delta T=0$, the maximum flux is that corresponding to an isothermal free laminar 
Diffusional flow under non-isothermal laminar free convention

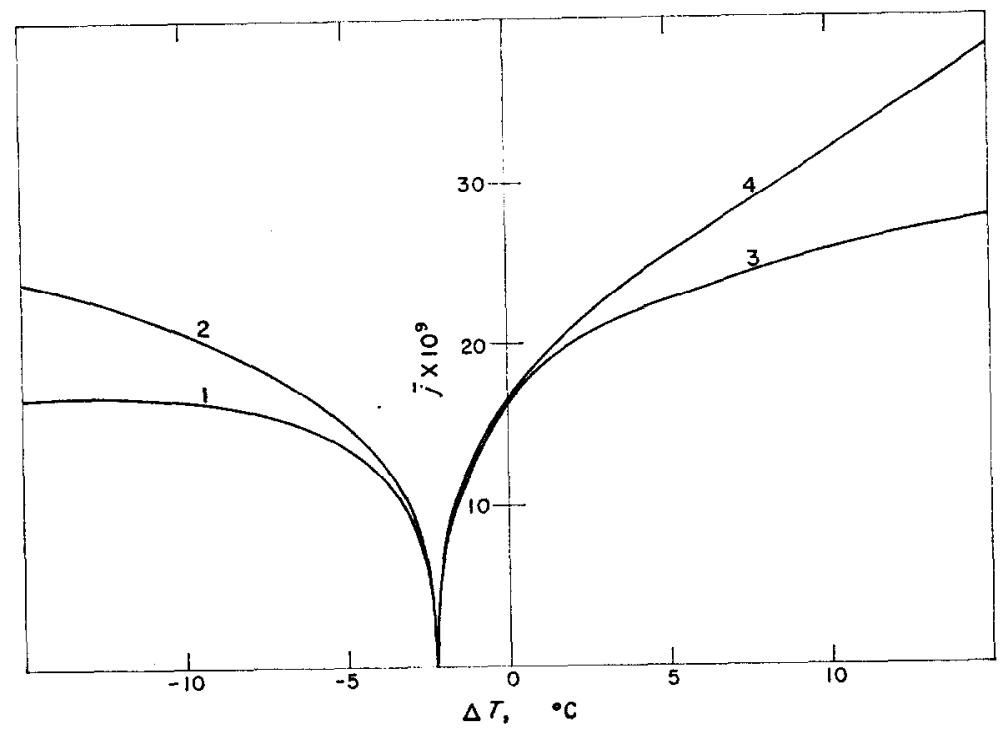

Fig. 5. Plot of $J$ against $\Delta T$.

$C, 0.05 \mathrm{M}$. The conditions relating to each curve are given in the text.

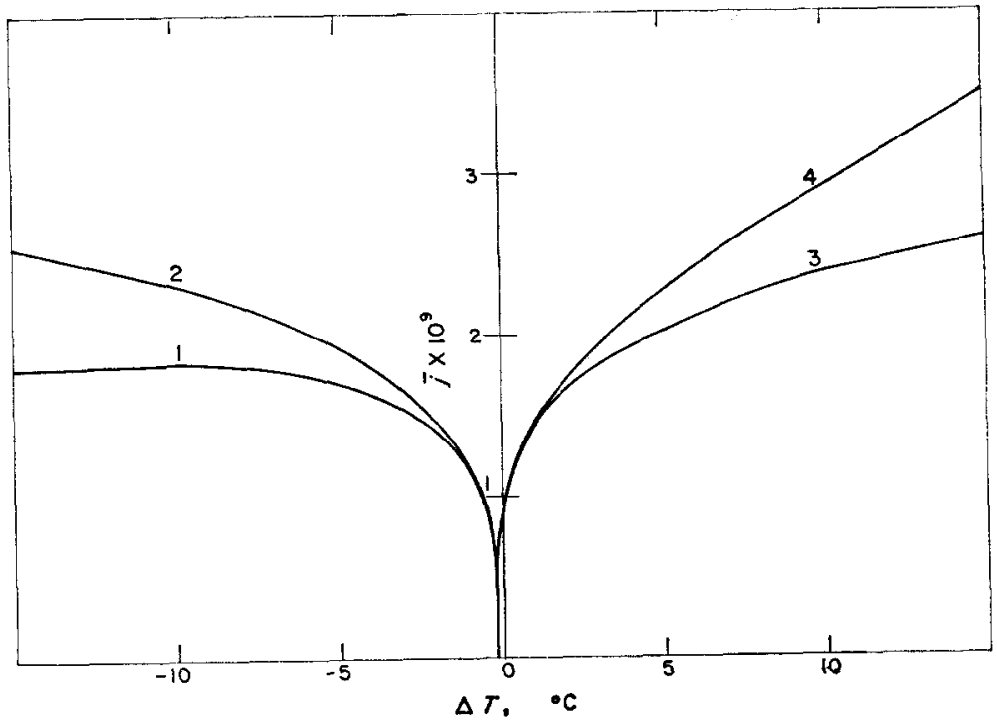

Fig. 6. Plot of $J$ against $\Delta T$.

$C, 0.005 \mathrm{M}$. The conditions relating to each curve are given in the text. 
convection process under a concentration gradient whose value results from Levich's equation. When $\Delta T$ decreases $J$ decreases continuously, approaching zero at $(\Delta T)_{\bar{J}=0}$. From (36), this situation arises when

$$
\frac{\alpha^{3 / 4}}{S c^{1 / 4}}=\frac{\beta^{3 / 4}}{\operatorname{Pr}^{1 / 4}}
$$

The fact that $J$ becomes zero means that at $(\Delta T)_{\bar{J}=0}$, the velocity component in the $x$ direction due to the thermal gradient is exactly compensated by that due to the concentration gradient. Consequently the process approaches an ideal diffusion process, for which no steady flux is obtained with the present ideal model. ${ }^{18}$ At $\Delta T<(\Delta T)_{j=0}, J$ begins to increase because under these circumstances there is again a net velocity component.

$(\Delta T)_{\vec{j}=0}$ depends on the concentration of the reacting species and when the latter decreases, $(\Delta T)_{\bar{J}=0}$ approaches zero. This is clearly shown in Fig. 6, where the concentration is ten times lower than that in Fig. 5.

Another feature of those curves, which is related both to those already analysed and to the change of the physicochemical properties of the fluid with temperature, is their asymmetry with respect to $(\Delta T)_{j=0}$. The latter effect also contributes to the appearance of a slight maximum in the plot of Figs. 5 and 6 for negative $\Delta T$ values, at decreasing reference and plate temperatures. The maximum is better defined at lower values of $\alpha$.

\section{APPLICATION TO A VERTICAL PLANE THERMAL CONVECTIVE ELECTRODE}

For an electrochemical system involving a vertical plane working electrode, where the electrode reaction is under non-isothermal, free convection-diffusion control, we can write the average maximum flux in terms of the limiting cd $i_{\mathrm{L}}$, as

$$
i_{L}=0.90 z F D C_{0}\left(\frac{\alpha^{3 / 4}}{S c^{1 / 4}} \pm \frac{\beta^{3 / 4}}{\operatorname{Pr}^{1 / 4}}\right)^{1 / 3} S c^{1 / 3}\left(\frac{g}{4 v^{2}}\right)^{1 / 4} X^{-1 / 4}
$$

where $z$ is the number of electrons entering the electrochemical reaction and $F$ the Faraday constant.

Ducret and Cornet ${ }^{13}$ have recently employed an electrochemical device called by the authors "electrode á convection thermique". In this set-up the stirring was induced by a thermal gradient and it was applied to different electrochemical systems. The results in principle fit qualitatively well within the predictions the equation here proposed. Unfortunately, the published data are not suitable for a quantitative test of the theoretical equation because of the arbitrary geometry of the cells employed. Besides, the authors plot the results taking the maximum flux (in terms of current) against the amount of heat exchanged per unit area. Nevertheless with the exception of a constant factor, their plot is directly comparable to those shown in Figs. 5 and 6

A detailed experimental test of the rate equation derived in the present work has been performed employing an electrolysis cell with a geometry approaching the ideality involved in the present derivation. The results will be reported in the near future.

Finally, the present study shows the importance of keeping a constant temperature over the whole electrochemical set-up when ionic-mass transfer rates are measured, particularly in free convection or at a low rate of stirring. The discrepancies of results 
sometimes observed in this type of work may in part be due to temperature gradients originating in the systems.

Acknowledgement-The authors thank the Consejo Nacional de Investigaciones Cientificas y Técnicas of Argentina for partial financial support.

\section{REFERENCES}

1. V. G. Levich, Physicochemical Hydrodynamics. Prentice-Hall, Englewood Cliffs, N.J. (1962).

2. R. B. Bird, W. E. Steward and E. N. LightFoor, Transport Phenomena. Wiley, New York (1962).

3. C. WAGNER, J. electrochem. Soc. 95, 161 (1949).

4. C. W. ToBIAS, M. EIsENBERG and C. R. WiLKE, J. electrochem. Soc. 99, 359C (1952).

5. C. R. WiLKe, M. EISENBerg and C. W. ToBIAS, J. electrochem. Soc. 100, 513 (1953).

6. C. R. WruKe, C. W. Tobias and M. EISENBerg, Chem. Engng. Progr. 49, 663 (1953).

7. N. IBL and R. H. MÛ́LLER, J. electrochem. Soc. 105, 346 (1958).

8. N. IBL, Chem. Ing. Tech. 35, 353 (1963).

9. E. Polnhausen, Z. angew. Math. Mech. 1, 115 (1921).

10. M. TEN BosCH, Die Wärmeübertragung, III Aufiage, p. 160. Springer, Berlin (1936).

11. G. H. KeulegAN, J. Res. Nat. Bur. Stand. 47, 156 (1951).

12. N. G. Hirl, E. Det CASAI and D. W. ZeH, Int. J. Heat Mass Transf. 8, 1135 (1965).

13. L. DuCRET and C. CORNET, J. electroanal. Chem. 11, 317 (1966).

14. A. J. Arvia, S. L. Marchiano and J. S. W. Carrozza, Report to the Nat. Res. Council of Argentina (1963).

15. International Critical Tables, Vol. III and V. McGraw-Hill, New York (1928).

16. Handbook of Chemistry and Physics, 46th Edn., ed. C.D. Hodgman. Chem. Rubber Publishing, Cleveland (1966).

17. A. J. Arvia, J. C. BazÁn and J. S. W. Carrozza, Electrochim. Acta 11, 881 (1966).

18. P. DeLAHAY, New Instrumental Methods in Electrochemistry, p. 47. Interscience, New York (1958). 